\title{
Partial seasonality of breeding in red-necked wallabies (Macropus rufogriseus banksianus)
}

\author{
Karen Higginbottom ${ }^{1 * \dagger}$ and Christopher N. Johnson ${ }^{2}$ \\ ${ }^{1}$ Department of Ecosystem Management, University of New England, Armidale NSW 2351, Australia \\ ${ }^{2}$ Department of Zoology and Tropical Ecology, James Cook University, Townsville, Qld 4811, Australia \\ (Accepted 2 July 1999)
}

\begin{abstract}
Reproductive data on individually known free-ranging red-necked wallabies Macropus rufogriseus banksianus were obtained over a 6 year period. Although this subspecies is essentially a non-seasonal continuous breeder, more young wallabies emerged permanently from the pouch in spring than in any other season. This partial seasonality of breeding was the combined result of seasonal variation in duration of pouch lives, a tendency for the first young of females to emerge permanently in spring, and seasonal variation in the incidence of reproductive interruptions. It is proposed that the adaptive significance of this partial seasonality is that it maximizes juvenile survival while maintaining a high reproductive rate.
\end{abstract}

Key words: Macropodidae, marsupial, reproduction, seasonality, life history, Macropus rufogriseus banksianus

\section{INTRODUCTION}

In strongly seasonal environments, all females in a population are expected to breed at one optimal time of year; while in unpredictable environments, there should be selection for mechanisms which allow females to adjust the resources they channel into reproduction according to the relative costs and benefits at that particular time (Stearns, 1976; Carlisle, 1982; CluttonBrock, 1991).

Most macropodid marsupials live in Australia, a continent generally without extreme seasonal fluctuations in climate, but with high inter-annual unpredictability in rainfall. Thus, most macropodid species breed continuously or opportunistically, rather than seasonally (Tyndale-Biscoe, 1989). However, those authors who have looked in detail at species living in areas where seasonal climatic variation is relatively predictable have often found evidence of partial seasonality of breeding (e.g. Russell \& Richardson, 1971: antilopine wallaroo; Bolton, Newsome \& Merchant, 1982: agile wallaby; Kirkpatrick, 1965a; Kavanagh, 1977; Taylor, 1982; Stuart-Dick, 1987: eastern grey kangaroo; Kaufmann, 1974: whiptail wallaby; K. A. Johnson, 1977: red-necked pademelon; Poole, 1973; Shepherd, 1987: western grey kangaroo).

\footnotetext{
*All correspondence to: Karen Higginbottom.

E-mail: k.higginbottom@mailbox.gu.edu.au

$\uparrow$ Present address: School of Environmental and Applied Science, Griffith University, PMB 50, Gold Coast Mail Centre, Qld 9726, Australia
}

The term partial seasonality is used here to refer to variation in the incidence of any phase of the breeding cycle between seasons, but which does not follow a strictly seasonal pattern. Typically, the above authors noted highest frequencies of births during spring and summer, based on shot or captured population samples. The extent of seasonality in breeding within macropodid species may vary between areas according to the seasonality of the food supply (Shield, 1964; Russell \& Richardson, 1971; Bolton et al., 1982). In general, breeding seasonality among macropodids is greatest in southern Australia, where some species have strict breeding seasons, and is least in northern Australia. It has been speculated that breeding occurs at the time of year which will maximize either milk supply at peak lactation (Ealey, 1963; Shield, 1964), or the quality of herbage available to young when they are weaned (S. Cork \& L. Hinds, pers. comm.), or which minimizes the costs of lactation to mothers (K. A. Johnson, 1977). However, no studies have set out to determine these relationships or elucidate the mechanisms involved.

This paper reports the first longitudinal study of partial seasonality of breeding in free-ranging macropodids, provides preliminary evidence concerning its adaptive significance, and raises questions about the physiological mechanisms involved.

The study animals were red-necked wallabies Macropus rufogriseus banksianus, which are mediumsized macropodids occurring in forests of coastal eastern and south-east Australia. Unlike the seasonally breeding Bennett's wallaby $M$. $r$. rufogriseus from 
Tasmania, red-necked wallabies are considered to be continuous breeders (Merchant \& Calaby, 1981; Tyndale-Biscoe, 1989). However, McEvoy (1970) \& J. Merchant (pers. comm.) have commented (without presenting quantitative data) that relatively more births occur in spring and/or summer in free-ranging populations. Like most macropodids, red-necked wallabies display embryonic diapause associated with lactational quiescence, and post-partum oestrus (Tyndale-Biscoe \& Renfree, 1987). True anoestrus has not been recorded in red-necked wallabies. Mating normally results in production of a quiescent blastocyst whose development is reactivated near the end of pouch-life of the previous young. The trigger for reactivation is thought to be a decrease below some threshold level of the frequency of the tactile sucking stimulus (Renfree, 1979; Merchant, 1989), although this relationship has not been quantified. Here we call this trigger the "critical suckling decline'. The maximum duration of pouch-life in macropodids is thought to be set by the need to ensure that the pouch-young has left the pouch before the next young is born (Janssens \& Rogers, 1989).

Pouch-life in the study population of red-necked wallabies lasts $9.3 \pm 0.9$ months (range $7-12, n=115$ ). During about the last 2 months of pouch-life, young spend increasingly longer periods outside the pouch (C. N. Johnson, 1987), ending in permanent emergence from the pouch (PEP). Mothers continue to suckle their young intermittently for a further $4.4 \pm 0.7$ months $(n=31)$, during which period the young are known as 'young-at-foot' (YAF) (Higginbottom, 1991). Studies of red-necked wallabies in captivity show that gestation lasts $30 \pm 1.4$ days, and that the interval between birth and postpartum mating is no longer than $2 \mathrm{~h}$ (McEvoy, 1970; Merchant \& Calaby, 1981). If there is no postpartum conception, another oestrus occurs about 33 days later (Merchant \& Calaby, 1981). Thus, assuming the continuous breeding cycle is maintained, an inter-PEP interval of about 10.5 months is expected. Given that an adult female is estimated to live about 10 years (Higginbottom, 1991), her different breeding attempts would not be expected to be clustered during any particular time of the year even if the timing of first breeding were seasonal. Thus, in the absence of any mechanism promoting seasonal variation, one would predict an even spread of young emerging permanently from the pouch throughout the seasons.

\section{METHODS}

\section{General}

The 158 ha study area (described by Jarman, Johnson et al., 1987) is at 'Wallaby Creek' $\left(152^{\circ} 45^{\prime} \mathrm{E}, 28^{\circ} 45^{\prime} \mathrm{S}\right)$ in sub-tropical north-east New South Wales, Australia, consisting mostly of semi-cleared cattle grazing properties. The study area was inhabited by a median of 61 adult and sub-adult red-necked wallabies, including 40 adult females. Data were collected from March 1981 to
October 1987 during monthly field trips of $c .10$ days and including a continuous period of 8 months. All adults were individually recognizable and well habituated to humans (Jarman, Jones et al. 1989), who carried out observations on foot with the aid of binoculars.

\section{Female life history data}

For each adult female, the timing of each successive oestrus was inferred from the behaviour of courting males (C. N. Johnson, 1989). Parturition was assumed to have occurred when 1 oestrus was not followed by another 28-40 days later. The presence and size class of pouch-young were assessed visually on a monthly basis. Size classes were: (1) no pouch-young or pouch-young $<3$ months old: no definite pouch bulge; (2) pouchyoung 3-6 months old: definite pouch bulge but head kept inside the pouch; (3) pouch-young $>6$ months old: pouch young with head out of the pouch at least some of the time. The timing of each successive PEP was also recorded. Specific efforts were made to find and observe females and their young around the time at which PEP was expected to occur. We determined that PEP had occurred if the mother and young were out of sight of each other or, if together, the young did not re-enter the pouch when alarmed. Records were obtained relating to the production of 240 young.

A female was described as breeding continuously if a single oestrus was followed by a pouch-life ending in PEP and then by another oestrus about 30 days later. The interval between each successive oestrus was termed a 'continuous cycle'. During all periods when a female was not breeding continuously, she was described as experiencing a 'reproductive interruption'.

Reproductive interruptions took 3 observed forms: (1) A female was recorded as having lost a pouchyoung if a visible bulge in her pouch suddenly disappeared before the young reached 7 months of age (the earliest observed age at PEP according to our data). The short inter-oestrus interval involved was called a lost pouch-young cycle.

(2) A female was recorded as having failed to produce or maintain a viable blastocyst if after PEP of 1 young she experienced 2 or more consecutive oestruses (separated by the length of an oestrous cycle). This could have occurred through a failure to come into oestrus, to mate, to conceive or to subsequently produce a viable blastocyst just after the previous young's parturition. The birth of the next young would coincide with the last consecutive oestrus. The interval between the first and last consecutive oestrus was termed a failed blastocyst cycle, although we note that initial failure of the blastocyst may have occurred before the pouch-life of the young which had just emerged permanently from the pouch.

(3) A female was recorded as experiencing a reproductive gap if after PEP of the last young there was no subsequent evidence of a pouch-young nor of oestrus for at least 70 days (i.e. greater than the length of 


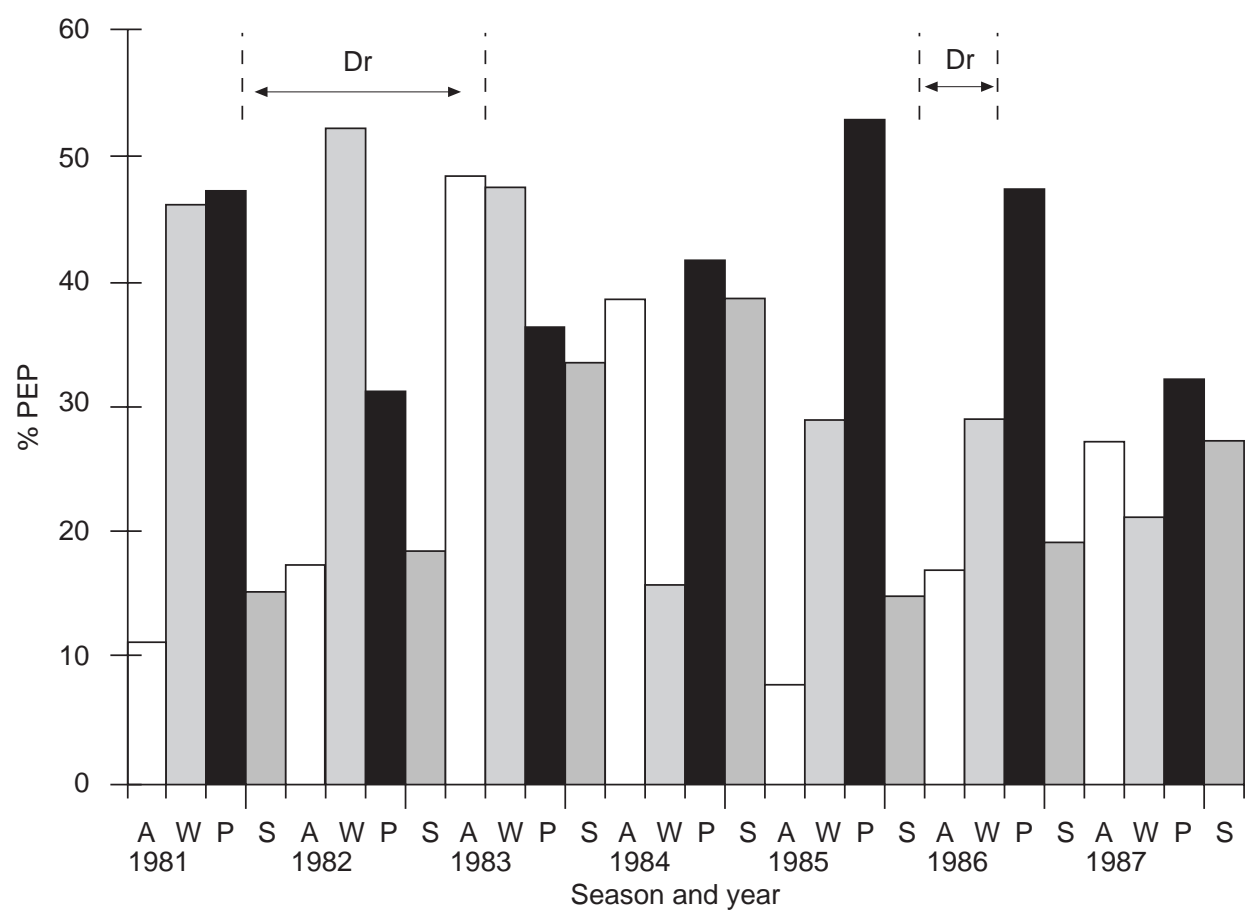

Fig. 1. Estimated percentages of females with young emerging permanently from the pouch in each season of the study period. A, autumn; W, winter; P, spring; S, summer; Dr, drought; \% PEP, percentage of females with young reaching permanent emergence from the pouch.

2 oestrous cycles). A reproductive gap cycle was defined as the interval between PEP and the subsequent oestrus within the latter context.

It was sometimes impossible to distinguish between different forms of reproductive interruptions because of non-continuous monitoring of individuals and because the presence of a pouch-young could usually not be ascertained before it reached 3 months of age and produced a visible bulge in the pouch.

Primiparous females were defined as those which had experienced their first conception but whose first young had not yet reached PEP. If a female was conceiving for the first time, she would initially experience 2 consecutive oestruses separated by an oestrous cycle, the second oestrus corresponding to birth of her first young.

The numbers of monitored females with and without young emerging permanently from the pouch were recorded for each season (defined by Australian convention). For all but the first year of data collection, the monitored females included at least $95 \%$ of those with at least half of their home range within the study area.

\section{RESULTS}

Although in $87 \%$ of reproductive cycles, female rednecked wallabies bred continuously, between $2.2 \%$ and $4.9 \%$ of cycles involved a reproductive gap, and in an estimated $3 \%$ of reproductive cycles, females failed to produce a viable blastocyst (total $n=223$ reproductive cycles). Death of pouch-young was estimated to occur in $4.5 \%$ to $8.0 \%$ of reproductive cycles. The range in these estimates resulted from inability to distinguish between reproductive gaps and lost pouch-young in some cases.

In 5 of the 7 years during which the population was monitored, a peak in permanent emergence of young occurred in spring (Fig. 1). The 2 years when this did not happen were during and soon after a long drought. Overall, the relative numbers of monitored adult females whose young emerged permanently from the pouch differed between seasons (Table 1), with a greater proportion emerging in spring than other seasons, and fewest in summer and autumn. There was a less marked spring peak in the timing of oestrus.

There are two ways in which seasonal variation in the incidence of PEPs might arise: multiparous females might experience seasonal variation in inter-PEP intervals and/or primiparous females might give birth to their first young at a time which resulted in their first young reaching PEP in spring.

In investigating the first possibility, we calculated the month when each successive PEP of a young was predicted to occur based on timing of the previous PEP, and assuming continuous breeding and mean pouch-life durations. Each observed PEP was then classified as 'early' if it was in a month earlier than predicted, 'ontime' if it occurred in the predicted month and 'late' if it was in a month later than predicted. There was seasonal variation in the extent to which PEPs were 'early', 'ontime' or 'late' (Table 2), which was a result of primarily more PEPs being 'late' in spring than in other seasons, and secondarily to more PEPs being 'early' in summer. PEPs occurring in autumn and winter were most likely 
Table 1. Monitored adult females experiencing oestrus and PEP in each season. Expected values given no seasonality are in parentheses. Test of homogeneity between seasons for PEP: $\chi^{2}{ }_{3}$ d.f. $=18.2, P<0.001$. Test of homogeneity between seasons for oestrus: $\chi^{2}{ }_{3}$ d.f. $=7.9, P<0.05$

\begin{tabular}{|c|c|c|c|c|c|}
\hline Females & Spring & Summer & Autumn & Winter & Total \\
\hline With PEP young & 83 ( 61.6) & $51(65.7)$ & $49(59.5)$ & $65(61.2)$ & 248 \\
\hline Without PEP young & $124(145.4)$ & $170(155.3)$ & $151(140.5)$ & $141(144.7)$ & 586 \\
\hline$\%$ with PEP young & 40 & 23 & 25 & 32 & \\
\hline In oestrus & $83(69.7)$ & $76(74.5)$ & $54(67.4)$ & $68(69.4)$ & 281 \\
\hline Not in oestrus & $124(137.3)$ & $145(146.5)$ & $146(132.6)$ & $138(136.6)$ & 553 \\
\hline$\%$ in oestrus & 40 & 34 & 27 & 33 & \\
\hline Total no. females & 207 & 221 & 200 & 206 & 834 \\
\hline
\end{tabular}

Table 2. Number of young emerging permanently from the pouch in each season in relation to the month predicted from timing of previous PEP for multiparous females. Expected values given no seasonality are in parentheses. Test of homogeneity between seasons: $\chi_{6}^{2}=19.8, P<0.01$

\begin{tabular}{lcllc}
\hline Season at PEP & Early & On time & Late & Total \\
\hline Summer & $14(9.2)$ & $13(9.2)$ & $11(13.0)$ & 38 \\
Autumn & $14(9.7)$ & $16(9.7)$ & $10(13.7)$ & 40 \\
Winter & $6(10.9)$ & $27(10.9)$ & $12(15.4)$ & 45 \\
Spring & $9(13.3)$ & $18(13.3)$ & $28(18.8)$ & 55 \\
Total & 43 & 74 & 61 & 178 \\
\hline
\end{tabular}

Table 3. Analysis of variance on factors relating to pouch life duration

\begin{tabular}{llll}
\hline Variable & $F$ & d.f. & $P$ \\
\hline Sex of young & 5.64 & 1 & 0.02 \\
Home-range location & 3.42 & 1 & 0.07 \\
Sex of young $\times$ home-range location & 5.69 & 1 & 0.02 \\
Season $\times$ home-range location & 5.04 & 1 & 0.03 \\
\hline
\end{tabular}

to be 'on-time'. Further, of those 20 PEPs that occurred in a season other than that predicted, 16 were 'late' PEPs predicted to occur in winter, which instead occurred in spring.

Most (21 of 28) 'late' spring PEPs were a result of unusually long pouch-life durations. The remainder was due to reproductive interruptions, comprising four lost pouch-young cycles, one failed blastocyst cycle, two reproductive gap cycles and four that were impossible to categorize. All of the early summer PEPs were the result of unusually short pouch-life durations.

To investigate the apparent role of variable pouch-life duration in producing partial seasonality of breeding, we tested whether pouch-life duration varied with season of PEP. When entered into an analysis of variance with other factors related to pouch-life duration (Table 3), season was not significant alone, but there was a significant interaction between season and home-range location. This was explained by the effect of season applying only to wallabies from the more fertile southern valley area (for southern wallabies: mean pouch-life duration for young PEP in spring/winter was 9.5 months, $n=37$; PEP in summer/autumn was 8.8 months, $n=18$; combining of seasons was necessary to provide adequate cell sizes).

Seasonal variation in the incidence of reproductive interruptions was similarly investigated. A reproductive interruption was recorded as occurring in the month when females experienced loss of pouch-young, a failed blastocyst, or the beginning of a reproductive gap. Records of uninterrupted breeding by females in each season were restricted to females at stages in their breeding cycle when it was possible for them to experience a reproductive interruption as defined here (i.e. excludes females with large pouch-young). Such interruptions were much more likely to occur in summer than in other seasons (summer: 19 interrupted, 340 uninterrupted; other seasons combined as required for adequate cell sizes: eight interrupted, 979 uninterrupted; $\chi^{2}{ }_{1}=24.7, P<0.01$ ), which tended to have the result that the subsequent PEP would occur in spring. In particular, losses of pouch-young (which were also predominant in summer) were more likely to be followed by a PEP in spring than in any other season $\left(\chi_{3}^{2}=11.3, P<0.05\right)$, since a return to oestrus in summer followed by an average pouch-life duration resulted in a spring PEP. Sample sizes for reproductive gaps and failed blastocysts were insufficient for statistical analysis, although the same trends were apparent.

Among females known to be primiparous, $62 \%$ of their first recorded PEPs occurred in spring (spring 16 PEPs, other seasons combined 10 PEPs; $\chi^{2}{ }_{1}=16.6$, $P<0.001$; combining of seasons necessitated by small cell sizes), corresponding to the general seasonal bias but apparently being more pronounced. At least four of these spring PEPs resulted from loss of pouch-young, and at least a further four resulted from other types of reproductive interruptions. It was not clear to what extent the remainder reflected partial seasonality in occurrence of first oestrus, since courting of these females was prolonged over a period of months and therefore the timing of oestrus was difficult to ascertain. When we calculated the number of primparous mothers which would have their first PEP in each season, based on the seasonal distribution of their own PEPs and the mean age at first breeding, there were still many more spring PEPs than expected $\left(\chi_{1}^{2}=14.1, P<0.001, n=26\right)$. At least eight of the 10 definite pouch-young losses in 
the population occurred in primiparous females, and at least six of the 26 primiparous females lost their first pouch-young.

\section{DISCUSSION}

Red-necked wallabies at Wallaby Creek displayed partial seasonality of breeding, apparently as the combined result of seasonal variation in several aspects of female reproduction. These were pouch-life durations, incidence of PEP of the first young of primiparous females, and incidence of reproductive interruptions. The net result was that there was a spring peak in the incidence of PEP. Two main questions arise: whether such a pattern has adaptive value, and what physiological processes or mechanisms are involved.

In terms of adaptive value, we propose that the tendency to have young reaching PEP in spring is a response to selection because it results in increased survivorship of young. The largest component of variation in the reproductive success of a female in this population was the number of her young that survived from PEP to weaning (Higginbottom, 1991). This in turn was significantly related to season of PEP. The latter relationship was significant during good climatic conditions, when survival was highest for young reaching PEP in spring ( $73 \%$ survival), followed by winter $(62 \%)$, autumn $(59 \%)$ and then summer $(50 \%)$, but not during drought conditions.

Two factors are expected to have the greatest influence on survivorship of young-at-foot, which could be influenced in turn by season: intensity of predation pressure, and nutritional supply affecting the forage supply and/or maternal milk supply. A third factor suggested by Kaufmann (1974) is that avoidance of cold stress may be important, but if this applied we would expect survival to be highest in summer and lowest in winter, which was not the case.

If there were seasonal variation in predation pressure on young-at-foot at Wallaby Creek, this might be expected to result from seasonal variation in the number of dingoes. Dingoes are the wallabies' main predator in this area, and prey mostly on young-at-foot. There was no consistent pattern of variation in relative abundance of dingoes in the study area across seasons (Higginbottom, 1991; data collated from P. J. Jarman, C. N. Johnson, R. I. Stuart-Dick, J. Clarke \& C. Southwell, pers. comm.). However it remains possible that other factors influencing predation pressure from dingoes vary seasonally. Further, any natural pattern of seasonal variation in dingo numbers could be obscured by the practice of trapping by farmers.

Seasonal variation in nutrition may provide an adaptive explanation for the observed pattern of breeding. There was substantial and consistent variation in the quantity and quality of food available to wallabies across seasons at Wallaby Creek (Higginbottom, 1991). Digestibility of plant species eaten by red-necked wallabies, as indicated by species composition, nitrogen and fibre content (cf. Hume, 1982; 1987) was at its highest in spring. This may have an effect on survival of young-at-foot through its influence on maternal lactation and/or the young's forage supply.

The disruption of the pattern of partial seasonality during drought could be related to the apparent greater unpredictability in the food supply, although this was not assessed quantitatively. A lesser degree of seasonality in breeding during drought has also been found for red and western kangaroos, in which the predictable seasonality in food supply was dramatically reduced during drought (Shepherd, 1987).

Turning to the mechanisms involved in producing partial seasonality of breeding, the first of these was seasonal variation in pouch-life durations that seem to be very labile; ranging from 7 to 11.5 months in this population. Captive M. rufogriseus (fed ad libitum) apparently produce young with shorter pouch-lives than those at Wallaby Creek (see Kirkpatrick, 1965b; Merchant \& Calaby, 1981; Fleming, Cinderey \& Hearn, 1983), which is consistent with the explanation that pouch-life duration is determined by the young's body weight. In the study population, longer pouchlives for young reaching PEP in spring could be explained by their mothers experiencing relatively poor nutrition in winter. The restriction of the relationship between season and pouch-life duration to southern valley wallabies may be related to more marked seasonal variation in nutrition in that part of the study area.

There are two components contributing to the length of pouch-life: the timing of the critical suckling decline (which triggers reactivation of the blastocyst and subsequent parturition), and the length of the period during which the young continues to enter the pouch after critical suckling decline, but before birth of the next young. We estimate that PEP occurred on average only 4.9 days after the critical suckling decline, though potentially ranging from 0 to 11.5 days (based on PEPoestrus intervals from the present study of $22.6 \pm 3.4$ days, range 18-28, $n=14$; compared with delayed gestation lengths recorded by Merchant \& Calaby (1981) of $27.5 \pm 1.3$ days, range 26-29.5). As this period is relatively short, it is less likely to be important in determining pouch-life duration than is the timing of the critical suckling decline. The latter may be proximately determined by the mother's behaviour, as she controls the amount of time her young spends outside the pouch (C. N. Johnson, 1987; Russell, 1989). This could in turn be determined by the young's body weight, potentially mediated by thermal intolerance (Janssens \& Rogers, 1989). However, the relationships between timing of critical suckling decline, time the young spends outside the pouch and its body weight are not known.

The second most important cause of partial seasonality was the tendency for primiparous females to have their first young reaching PEP in spring, which would typically follow a parturition in summer. This tendency was probably partly the result of a tendency for a 
female's first oestrus to occur in summer. In the strictly seasonal M. r. rufogriseus, summer parturition results from seasonal quiescence suppressing activity of the corpus luteum until the summer solstice, resulting from a hormonal response to increases in daylength (Loudon, Curlewis \& English, 1985). This is seen as a secondary pattern derived from the basic macropodid pattern (Tyndale-Biscoe, 1989). The same pattern of apparent seasonal quiescence has also been noted in captive M. r. banksianus, such that parturition failed to occur until after the summer solstice (Tyndale-Biscoe, 1989). Perhaps in M. r. banksianus a hormonal response to daylength is involved which comes into play only when females are in relatively poor condition in the preceding period.

The final factor contributing to partial seasonality of breeding was the tendency for reproductive interruptions, including at least the loss of pouch-young, to be most likely to occur in summer. Reproductive interruptions were also much more prevalent during and just after the long drought, and in females from the less fertile part of the study area (Higginbottom, 1991), suggesting that they occurred when females were in poor condition and/or poor forage was available. However, it seems unlikely that the loss of pouch-young tends to occur in summer because of females being in poorest condition at that time, since food biomass is then at its peak and digestibility is moderate. Instead we speculate that it could be an adaptive response that is somehow connected with hormonal changes related to daylength: if a female is in relatively poor condition, then perhaps it becomes adaptive for her to delay reproduction until a time when optimum environmental conditions at PEP will compensate for her own lack of resources (cf. Parker, 1977; Carlisle, 1982; Hayssen, Lacy \& Parker, 1985). If so, this is not a peculiarly marsupial ability, since some eutherians are thought to adaptively abort or resorb litters (Lee \& Cockburn, 1985). However, to date there is no evidence of relevant mechanisms in marsupials.

Some form of anoestrus may occasionally occur in red-necked wallabies. This seemed to apply to all the recorded reproductive gaps and to an unknown proportion of events recorded as failed blastocysts, in which the female failed to come into oestrus before the preceding pouch-life. Since it occurred mainly during or shortly after drought (Higginbottom, 1991), we propose that anoestrus represents a response to extreme nutritional deprivation in this species.

This study provides preliminary evidence that by virtue of their mode of reproduction, macropodid marsupials display a complex and flexible strategy for timing of breeding. The fact that seasonality of breeding in this population was only partial indicates that the wallabies may be optimizing the trade-off between maximizing survival of individual offspring and maximizing reproductive rate. These findings complement recent evidence that the marsupial mode of reproduction facilitates adaptive sex allocation (e.g. Cockburn, 1994). It has often been argued that it is less costly for a marsupial displaying embryonic diapause to lose a small pouch-young than for a placental to abort a young, as it will be more quickly replaced (e.g. Low, 1978). Further, the opportunities for varying the length of pouch-life in marsupials may be greater than those for varying gestation length in placentals. However, without more investigation of the mechanisms involved we cannot say whether partial seasonality of breeding in red-necked wallabies represents facultative adaptation or a passive response to a seasonal pattern of environmental variation.

\section{REFERENCES}

Bolton, B. L., Newsome, A. E. \& Merchant, J. C. (1982). Reproduction in the agile wallaby Macropus agilis (Gould) in the tropical lowlands of the Northern Territory: opportunism in a seasonal environment. Aust. J. Ecol. 7: 261-277.

Carlisle, T. R. (1982). Brood success in variable environments: implications for parental care allocation. Anim. Behav. 30: 824-836.

Clutton-Brock, T. H. (1991). The evolution of parental care. Princeton, NJ: Princeton University Press.

Cockburn, A. (1994). Adaptive sex allocation by brood reduction in antechinuses. Behav. Ecol. Sociobiol. 35: 53-62.

Ealey, E. H. M. (1963). The ecological significance of delayed implantation in a population of the hill kangaroo (Macropus robustus) In Delayed implantation: 33-47. Enders, A. C. (Ed.). Chicago: University of Chicago Press.

Fleming, D., Cinderey, R. N. \& Hearn, J. P. (1983). The reproductive biology of the Bennett's wallaby (Macropus rufogriseus rufogriseus) ranging free at Whipsnade Park. J. Zool.(Lond.) 201: 283-291.

Hayssen, V., Lacy, R. C. \& Parker, P. J. (1985). Metatherian reproduction: transitional or transcending? Am. Nat. 126: 617-632.

Higginbottom, K. (1991). Reproductive success and reproductive tactics in female red-necked wallabies. $\mathrm{PhD}$ thesis, Armidale, University of New England.

Hume, I. D. (1982). Digestive physiology and nutrition of marsupials. Cambridge: Cambridge University Press.

Hume, I. D. (1987). Native and introduced herbivores in Australia. In The nutrition of herbivores: 1-22. Hacker, J. B. \& Ternouth, J. H. (Eds). Sydney: Academic Press.

Janssens, P. A. \& Rogers, A.M.T. (1989). Metabolic changes during pouch vacation and weaning in Macropodoides. In Kangaroos, wallabies and rat kangaroos: 367-376. Grigg, G., Jarman, P. \& Hume, I. D. (Eds). Australia: Surrey Beatty \& Sons.

Jarman, P. J., Johnson, C. N., Southwell, C. J. \& Stuart-Dick, R. (1987). Macropod studies at Wallaby Creek. I. The area and animals. Aust. Wildl. Res. 14: 1-14.

Jarman, P. J., Jones, M. E., Johnson, C. N., Southwell, C. J., Stuart-Dick, R. I., Higginbottom, K. B. \& Clarke, J. L. (1989). Macropod studies at Wallaby Creek. VIII. Individual recognition of kangaroos and wallabies. Aust. Wildl. Res. 16: 179-85.

Johnson, C. N. (1987). Relationships between mother and infant red-necked wallabies (Macropus rufogriseus banksianus). Ethology 74: 1-20.

Johnson, C. N. (1989). Social interactions and reproductive tactics in red-necked wallabies (Macropus rufogriseus banksianus). J. Zool. (Lond.) 217: 267-280.

Johnson, K. A. (1977). Ecology and management of the red-necked pademelon Thylogale thetis on the Dorrigo plateau of northern New South Wales. PhD thesis, Armidale, University of New England. 
Kaufmann, J. H. (1974). Social ethology of the whiptail wallaby, Macropus parryi, in northeastern New South Wales. Anim. Behav. 22: 281-364.

Kavanagh, R. P. (1977). Age determination, growth rates and reproductive potential of grey kangaroos on the NE Tablelands. Diploma of Natural Resources thesis, Armidale, University of New England.

Kirkpatrick, T. H. (1965a). Studies of macropodidae in Queensland. 3. Reproduction in the grey kangaroo (Macropus major) in southern Queensland. Queensl. J. agric. Anim. Sci. 22: 319-328.

Kirkpatrick, T. H. (1965b). Studies of macropodidae in Queensland. 2. Age estimation in the grey kangaroo, the red kangaroo, the eastern wallaroo and the red-necked wallaby, with notes on dental abnormalities. Queensl. J. agric. Anim. Sci. 22: 301-317.

Lee, A. K. \& Cockburn, A. (1985). Evolutionary ecology of marsupials. Cambridge: Cambridge University Press.

Loudon, A. S. I., Curlewis, J. D. \& English, J. (1985). The effect of melatonin on the seasonal embryonic diapause of the Bennett's wallaby (Macropus rufogriseus rufogriseus). J. Zool. (Lond.) 206: 35-39.

Low, B. S. (1978). Environmental uncertainty and the parental strategies of marsupials and placentals. Am. Nat. 112: 197-213.

McEvoy, J. S. (1970). Red-necked wallaby in Queensland. Queensl. Agric. J. 96: 114-116.

Merchant, J. C. (1989). Lactation in macropodoid marsupials. In Kangaroos, wallabies and rat kangaroos: 355-366. Grigg, G., Jarman, P. \& Hume, I. D. (Eds). Australia: Surrey Beatty \& Sons.

Merchant, J. C. \& Calaby, J. H. (1981). Reproductive biology of the red-necked wallaby (Macropus rufogriseus banksianus) and the Bennett's wallaby (M.r. rufogriseus). J. Zool. (Lond.) 194: 203-217.

Parker, P. (1977). An ecological comparison of marsupial and placental patterns of reproduction. In The biology of marsu- pials: 273-286. Stonehouse, B. \& Gilmore, D. (Eds). London: MacMillan.

Poole, W. E. (1973). A study of breeding in grey kangaroos Macropus giganteus (Shaw) and M. fuliginosus (Desmarest) in central New South Wales. Aust. J. Zool. 21: 183-212.

Renfree, M. B. (1979). Initiation of development of diapausing embryo by mammary denervation during lactation in a marsupial. Nature (Lond.) 278: 549-551.

Russell, E. M. (1989). Maternal behaviour in the Macropodoidea. In Kangaroos, wallabies and rat kangaroos: 549-569. Grigg, G., Jarman, P. \& Hume, I. D. (Eds). Australia: Surrey Beatty \& Sons.

Russell, E. M. \& Richardson, B. J. (1971). Some observations on the breeding, age structure, dispersion and habitat of populations of Macropus robustus and Macropus antilopinus (Marsupialia). J. Zool. (Lond.) 165: 131-142.

Shepherd, N. (1987). Condition and recruitment of kangaroos. In Kangaroos: their ecology and management of the sheep rangelands of Australia: 135-158. Caughley, G., Shepherd, N. \& Short, J. (Eds). Cambridge: Cambridge University Press.

Shield, J. (1964). A breeding season difference in two populations of the Australian macropod marsupial (Setonix brachyurus). J. Mammal. 45: 616-625.

Stearns, S. C. (1976). Life-history tactics: a review of the ideas. Q. Rev. Biol. 51: 3-47.

Stuart-Dick, R. I. (1987). Parental investment in the eastern grey kangaroo. $\mathrm{PhD}$ thesis, Armidale, University of New England.

Taylor, R. J. (1982). The comparative ecology of the eastern grey kangaroo and the wallaroo on the north east tablelands of NSW. $\mathrm{PhD}$ thesis, Armidale, University of New England.

Tyndale-Biscoe, C. H. (1989). The adaptiveness of reproductive process. In Kangaroos, wallabies and rat kangaroos: 277-285. Grigg, G., Jarman, P. \& Hume, I. D. (Eds). Australia: Surrey Beatty \& Sons.

Tyndale-Biscoe, H. \& Renfree, M. (1987). Reproductive physiology of marsupials. Cambridge: Cambridge University Press. 